В.М.Провоторов, М.А.Никитин

Клиническая эффективность лечения больных
бронхиальной астмой и приобретенным
андрогенодефицитом с применением андриола

Воронежская государственная медицинская академия им. Н.Н. Бурденко: 394036, Воронеж, ул. Студенческая, 10

\title{
V.M.Provotorov, M.A.Nikitin \\ Clinical efficacy of andriol in patients with bronchial asthma and acquired androgen deficiency
}

\begin{abstract}
Summary
The aim of this study was to investigate influence of andriol replacement therapy on clinical course of asthma in patients with acquired androgen deficiency. Thirty six males in age of $53.5 \pm 2.4$ years with asthma history of 1 to 8 years were examined and treated. Besides of lung function and androgen status, quality of life was assessed before and after andriol replacement therapy. Results of the study showed favorable influence of the andriol replacement therapy on severity and frequency of asthma attacks as well as improvement in several parameters of the patients' quality of life. Key words: bronchial asthma, acquired androgen deficiency, andriol.
\end{abstract}

\section{Резюме}

Целью исследования было изучить влияние заместительной терапии препаратом тестостерона (андриолом) на особенности клиники у больных с приобретенным андрогенодефицитом. Были обследованы и пролечены 36 мужчин в возрасте $53,5 \pm 2,4$ года с длительностью заболевания от 1 до 8 лет. Помимо функции внешнего дыхания и андрогенного статуса у больных определялось качество жизни как до, так и после проведения заместительной терапии препаратом тестостерона (андриолом). Проведенное исследование показало положительное влияние заместительной терапии на тяжесть и частоту приступов у больных бронхиальной астмой, а также улучшение отдельных показателей качества жизни.

Ключевые слова: бронхиальная астма, приобретенный андрогенодефицит, андриол.

Многие исследователи подчеркивают роль эндокринных факторов в развитии бронхиальной астмы (БА). В сочетании с атопической сенсибилизацией или стероидным дисбалансом эти факторы могут значительно усложнить течение заболевания. В связи с этим проблема сочетания БА с андрогенной дисфункцией по-прежнему остается неразрешенной. Необходимо дальнейшее изучение взаимосвязи БА с андрогенодефицитом. Помимо широко известного андрогенного, анаболического, репродуктивного, психофизиологического и гемопоэтического действия андрогены оказывают и иммунологические влияние.

На фоне снижения уровня тестостерна в иммунной системе преобладают активирующие эффекты, проявляющиеся в повышении синтеза провоспалительных цитокинов интерлейкина-1 и фактора некроза опухоли- $\alpha$ (TNF- $\alpha)$ [1], определяющих образование интерлейкина-2 (Il-2), рецепторов к Il-2 и формирование цитотоксических Т- и NK-клеток. Данные изменения сопровождаются повышением уровня ряда цитотоксических факторов клеточного иммунитета: TNF- $\alpha$, гидролазы (кислая фосфатаза, щелочная фосфатаза, сериновые протеазы и эстеразы), компонентов комплемента, высокоактивных форм кислорода и азота, в значительной степени определяющих цитолитическое действие моноцитов, макрофагов, нейтрофилов, цитотоксических Т-и NK-клеток. У больных с PADAM (partial andro- gen deficiency of aging men) определяется повышенное содержание TNF- $\alpha$, кислой и щелочной фосфатаз.

N.Hamano et al. обнаружили, что тестостерон значительно сокращает способность эозинофилов инфильтрировать слизистые, их жизнеспособность и уменьшает их дегрануляцию [2]. Подтверждена взаимосвязь его концентрации в крови у женщин во время беременности с аллергическими заболеваниями у детей - БА, сенной лихорадкой, экземой и атопией. Концентрация тестостерона в материнской крови отрицательно связана с общим иммуноглобулином Е [3].

В некоторых исследованиях были выявлены различия аллергического воспаления дыхательных путей в зависимости от уровня тестостерона. При более высоком уровне тестостерона в крови бронхиальное воспаление является менее выраженным, наблюдается инфильтрация эозинофилов и лимфоцитов, причем количество этих клеток в бронхоальвеолярных путях уменьшается. Одновременно снижается и уровень интерлейкина-4. Более слабая воспалительная реакция дыхательных путей связана со снижением активности ответа Т-хелперных клеток 2-го типа (Тh2-клеток) [4].

Распространенность пищевой аллергии зависит от половой принадлежности: согласно результатам анкетирования, у женщин она возникает гораздо чаще, чем у мужчин. Тестостерон является иммуно- 
депрессантом и, вероятно, обеспечивает защиту, в то время как женские половые гормоны повышают восприимчивость к атопии [5].

Дигидроэпиандростендион может препятствовать производству Th2-цитокинов, хотя эффект от тестостерона и других андрогенов может оставаться менее определенным [6]. Изучено влияние тестостерона на регулирование Т-клеток и фенотипические особенности периферической крови: увеличение количества наиболее зрелых лимфоцитов $\left(\mathrm{CD}^{+}\right.$, $\mathrm{CD}^{-}$, и $\mathrm{CD}^{-}, \mathrm{CD}^{+}$) и фактора миграции, вырабатываемого тимусом. Кроме того, андрогены влияют на увеличение относительных и абсолютных показателей $\mathrm{CD} 4^{+}, \mathrm{CD} 25^{++} \mathrm{Fox}^{+}$и натуральных киллеров. Эти результаты сочетаются с чрезмерной экспрессией Т-хелперных клеток 1-го типа, которые, как предполагается, угнетают образование провоспалительных цитокинов [7].

Процессы активации комплемента, взаимодействия с мишенью цитотоксических Т- и NK-клеток, а также процессы дегрануляции и идентификации рецепторами NK-клеток антигенов, клеток-мишеней осуществляются при непосредственном участии кальция. В свою очередь, метаболизм кальция и витамина D находится под контролем тестостерона. Наличие рецепторов андрогенов и эстрогенов на поверхности лимфоцитов и макрофагов свидетельствует об их андрогенной и эстрогенной зависимости и объясняет причины изменений, происходящих в иммунной системе на фоне снижения уровня тестостерона, который в целом является иммунодепрессантом. С этим и связаны инволютивные изменения в лимфоидной системе, уменьшение продукции антител, угнетение бластной трансформации лимфоцитов. Андрогены оказывают избирательное воздействие на дифференцировку преимущественно В-лимфоцитов.

Целью настоящего исследования стало изучение влияния заместительной терапии препаратом тестостерона (андриолом) на качество жизни и течение заболевания у пациентов с БА и приобретенным андрогенодефицитом.

\section{Материалы и методы}

Были обследованы 36 мужчин в возрасте 50-56 лет, больных БА (средний возраст $-53,5 \pm 2,4$ года). Длительность заболевания составляла от 1 до 8 лет (медиана $(M e)-3$, интерквартильный размах $(25-75 \%)-2-5$ лет). Форма БА была среднетяжелой, персистирующей, частично контролируемой.

Основанием для включения в исследование являлось наличие анамнеза, характерного для БА, и типичных клинических симптомов данной патологии, подтвержденных оценкой функции внешнего дыхания (ФВД). Диагноз БА, ее форму, степень тяжести верифицировали согласно критериям Глобальной инициативы по лечению и профилактике бронхиальной астмы (GINA) 2006 г. и в соответствии с положениями Международной классификации болезней 10-го пересмотра. В исследование не включались па- циенты с тиреотоксикозом, гипотиреозом, сахарным диабетом, перенесшие острое нарушение мозгового кровообращения, с заболеваниями печени и почек с нарушением их функций.

Для выявления клинических признаков андрогенодефицита использовали Опросник симптомов старения мужчин - AMS (Aging Male's Symptoms' Rating Scale), предложенный L.A.Heinemann et al. в 1999 г., русскоязычная версия которого приведена в публикации И.И.Дедова и С.Ю.Калинченко [8]. Концентрацию общего тестостерона в сыворотке крови определяли методом иммуноферментного анализа (ИФА).

Критерием андрогенодефицита, согласно международным рекомендациям, считали уровень общего тестостерона < 12 нмоль / л. ФВД изучали посредством компьютерного спирографа КМ-АР-01 "Диамант" (Россия). Измеряли следующие показатели: объем форсированного выдоха за 1-ю с $\left(\mathrm{OФВ}_{1}\right)$, отношение ОФВ 1 к жизненной емкости легких (индекс Тиффно), форсированную жизненную емкость легких (ФЖЕЛ), мгновенную объемную скорость при выдохе 25, 50 и $75 \%$ ФЖЕЛ $\left(\mathrm{MOC}_{25}, \mathrm{MOC}_{50}\right.$ и $\left.\mathrm{MOC}_{75}\right)$. Перед проведением спирометрии отменяли $\beta_{2}$-агонисты короткого действия за 12 ч, длительного действия - за 24 ч до исследования. Объемную скорость выдоха определяли с помощью пикфлоуметра.

Качество жизни оценивали при помощи опросника SF-36, имеющего следующие шкалы:

- $\mathrm{PF}$ - физическое функционирование (в идеале 100 баллов);

- RP - ролевое функционирование (в идеале 100 баллов);

- $\mathrm{P}$ - боль (в идеале - 0 баллов);

- $\mathrm{GH}$ - общее здоровье (в идеале $-\leq 40$ баллов);

- VT - жизнеспособность (в идеале - 90 баллов);

- $\mathrm{SF}$ - социальное функционирование;

- $\mathrm{RE}$ - эмоциональное функционирование (в идеале - 100 баллов);

- МН - психологическое здоровье (в идеале 100 баллов).

Опросник позволяет оценить 2 основных параметра: физический компонент здоровья (1-4-я шкалы) и психический компонент здоровья (5-8-я шкалы).

Статистическая обработка полученных данных проведена с использованием программного пакета Statistica 6.0. Показатели представлены как $M \pm S D$, а также как Ме и интерквартильный размах (25-75\%). Различия считали статистически значимыми при $p<0,05$.

\section{Результаты и обсуждение}

По результатам ИФА, до лечения уровень тестостерона в сыворотке крови больных БА составил 7,6 $(4,8-9,2)$ нмоль / л. Всем пациентам была проведена заместительная терапия препаратом тестостерона (андриолом 40 мг per os) в течение 2 мес. В течение 1-го мес. препарат назначался в дозе 80 мг в сутки (для достижения насыщения), на протяжении 2-го мес. доза снижалась до 40 мг в сутки. После лечения 
Таблица 1

Количественная оценка показателей икал, опросника качества жизни SF-36 у больных БА до и после лечения с использованием андриола

\begin{tabular}{|l|c|c|}
\hline \multicolumn{1}{|c|}{ Показатель } & До лечения $(n=36)$ & После лечения $(n=36)$ \\
\hline PF, баллы & $55(25-95)$ & $55(40-95)$ \\
\hline RP, баллы & $0(0-25)$ & $25(0-50)$ \\
\hline P, баллы & $30(20-50)$ & $30(20-40)$ \\
\hline GH, баллы & $50(45-50)$ & $45(40-45)^{\star}$ \\
\hline VT, баллы & $45(40-55)$ & $50(40-55)$ \\
\hline SF, баллы & $62,5(50-62,5)$ & $62(50-75)$ \\
\hline RE, баллы & $33,3(0-66,6)$ & $33,3(33,3-66,6)$ \\
\hline MH, баллы & $56(52-72)$ & $64(60-72)^{\star}$ \\
\hline
\end{tabular}

Примечание: * $-p<0,05$.

провели повторное измерение уровня тестостерона, который повысился 10,3 (7,3-11,7) нмоль / л $(p<0,05)$. Для скринингового выявления андрогенодефицита среди больных БА использовали опросник AMS. Показатели в баллах до проведения терапии составили 41,3 (35-48,5) балла, после лечения - 38 (31-41) баллов при $(p<0,05)$.

В табл. 1 представлена количественная оценка вариабельности показателей шкалы опросника качества жизни SF-36 у пациентов с БА на фоне приобретенного андрогенодефицита до проведения заместительной терапии андриолом и после нее.

Показатели ФВД (ОФВ 1 , ФЖЕЛ, индекс Тиффно, $\mathrm{MOC}_{25}, \mathrm{MOC}_{50}, \mathrm{MOC}_{75}$ ), а также суточные колебания скорости выдоха у больных до и после лечения, измеренные посредством пикфлоуметрии, представлены в табл. 2. За время проведения терапии у пациентов были также проанализированы основные клинические показатели, характеризующие субъективное восприятие динамики заболевания. Было зарегистрировано уменьшение эпизодов одышки, свистящих хрипов, приступов кашля, заложенности в грудной клетке, ночных пробуждений из-за приступов БА, потребности в ингаляторах, а также улучшение отхождения мокроты и способности переносить физическую нагрузку (табл. 3).

Андриол назначался в дополнение к базисной терапии, включающей в себя применение ингаляционных глюкокортикостероидов в комбинации с $\beta_{2}$-агонистами длительного действия. Прием этих

Таблица 2

Показатели ФВДу больных БА до и после лечения с использованием андриола

\begin{tabular}{|c|c|c|}
\hline Показатель & До лечения ( $n=36$ ) & После лечения ( $n=36)$ \\
\hline $0 \mathbf{O B}_{1}, \%$ & $66,7 \pm 9,5$ & $69,0 \pm 8,4^{*}$ \\
\hline ФЖЕЛ, \% & $70,8 \pm 14,0$ & $73,2 \pm 12,4^{*}$ \\
\hline Индекс Тиффно & $82,8 \pm 13,8$ & $83,3 \pm 13,2$ \\
\hline $\mathrm{MOC}_{25}, \%$ & $52,3 \pm 18,0$ & $54,4 \pm 16,3^{*}$ \\
\hline $\mathrm{MOC}_{50}, \%$ & $49,7 \pm 16,3$ & $52,8 \pm 14,5^{\star}$ \\
\hline $\mathrm{MOC}_{75}, \%$ & $56 \pm 13,0$ & $59,3 \pm 11,3^{*}$ \\
\hline $\begin{array}{l}\text { Колебания } \\
\text { скорости выдоха }\end{array}$ & $14,2 \pm 4,2$ & $12,6 \pm 3,3^{*}$ \\
\hline
\end{tabular}

Примечание: * $-p<0,05$.
Таблица 3

Изменение клинических показателей на фоне проведенного лечения

\begin{tabular}{|c|c|c|c|}
\hline \multirow[t]{2}{*}{ Показатель } & \multicolumn{2}{|c|}{$n$ больных } & \multirow[t]{2}{*}{$p$} \\
\hline & абс. & $\%$ & \\
\hline Уменьшение свистящих хрипов & 6 & 16,6 & 0,025 \\
\hline Уменьшение одышки & 7 & 19,4 & 0,01 \\
\hline Уменьшение кашля & 7 & 19,4 & 0,01 \\
\hline Уменьшение заложенности в грудной клетке & 9 & 25 & 0,002 \\
\hline $\begin{array}{l}\text { Уменьшение ограничений повседневной } \\
\text { активности }\end{array}$ & 13 & 36,1 & 0,000 \\
\hline $\begin{array}{l}\text { Уменьшение ночных приступов } \\
\text { затрудненного дыхания }\end{array}$ & 10 & 27,7 & 0,001 \\
\hline $\begin{array}{l}\text { Уменьшение дневных приступов } \\
\text { затруднения дыхания }\end{array}$ & 7 & 19,4 & 0,01 \\
\hline $\begin{array}{l}\text { Уменьшение потребности в препаратах } \\
\text { неотложной помощи }\end{array}$ & 9 & 25 & 0,002 \\
\hline Улучшение отхождения мокроты & 6 & 16,6 & 0,025 \\
\hline
\end{tabular}

препаратов осуществлялся в режиме единого ингалятора с фиксированной комбинацией или посредством разных ингаляторов. Кроме того, больным назначали теофиллин замедленного высвобождения и холинолитики.

Среди нежелательных реакций, сопровождающих применение андриола, следует отметить анаболический эффект, проявляющийся увеличением массы тела, и отечный синдром, вызванный задержкой натрия и воды. После коррекции дозы эти явления исчезали.

Поскольку основные группы препаратов, применяемые в настоящее время в терапии больных БА, имеют побочное действие, заслуживает внимания уменьшение дозы, которое может быть достигнуто при совместном применении лекарственных средств, рекомендуемых GINA (2006), и препаратов тестостерона. Значимым положительным эффектом препаратов тестостерона является то, что они выступают как синергисты эндогенных глюкокортикоидов и стимулируют функциональную активность коры надпочечников.

\section{Заключение}

1. Результаты настоящего исследования свидетельствуют о положительном влиянии заместительной терапии андриолом на клинические проявления у больных БА с приобретенным андрогенодефицитом.

2. Заместительная терапия андриолом позволяет повысить отдельные показатели качества жизни пациентов с БА.

\section{Литература}

1. Печерский А.B. Частичный возрастной андрогенный дефицит. Влияние на развитие метаболического синдрома и патологии предстательной железы. СПб.: СПб МАПО; 2005.

2. Hamano N., Terada N., Maesako K. at al. Effect of sex hormones on eosinophilie inflammation in nasal mucosa. Allergy Asthma Proc. 1998; 19 (5): 263-269. 
3. Shaheen S.O., Hines M., Newson R.B. at al. Maternal testosterone in pregnancy and atopic outcomes in childhood. Allergy 2007; 62 (1): 25-32.

4. Hayashi T., Adachi Y., Hasegawa K. at al. Less sensitivity for late airway inflammation in males than females in BALB/c mice. Scand. J. Immunol. 2003; 57 (6): 562-567.

5. Osman $M$. Therapeutic implications of sex differences in asthma and atopy. Arch. Dis. Child. 2003; 88 (7): 587-590.

6. Chen W., Mempel M., Schober W. at al. Gender difference, sex hormones, and immediate type hypersensitivity reactions. Allergy 2008; 63 (11): 1418-1427.

7. Leposavic' G., Perisié, M., Kosec D. at al. Neonatal testosterone imprinting affects thymys development and leads to phenotypic rejuvenation and masculinization of the peripheral blood $\mathrm{T}$ - cell compartment in adult female rats. Brain Behav. Immun. 2009; 23 (2): 294-304

8. Дедов И.И., Калиниченко С.Д. Возрастной андрогенный дефицит у мужчин. М.: Практическая медицина; 2006.

\section{Информация об авторах}

Провоторов Вячеслав Михайлович - д. м. н., проф., зав. кафедрой факультетской терапии Воронежской государственной медицинской академии им. Н.Н. Бурденко; тел.: (4732) 52-07-77; e-mail: Никитин Максим Александрович - аспирант кафедры факультетской терапии Воронежской государственной медицинской академии им. Н.Н. Бурденко; тел.: 8-904-698-95-37; e-mail: jagdtigr@mail.ru УДК 616.248-085.357.45 